\title{
DESIGN GRÁFICO AMBIENTAL: REVISÃO E DEFINIÇÃO DE CONCEITOS
}

\author{
Fabiano de Vargas Scherer \\ Universidade Federal do Rio Grande do Sul | UFRGS \\ fabiano.scherer@ufrgs.br
}

\begin{abstract}
Resumo: Este artigo tem como objetivo apresentar e caracterizar a, relativamente nova, área de Design Gráfico Ambiental, e suas subáreas: Sinalização, Ambientação e Design de Exposições, através da revisão e definição de seus conceitos. Esta discussão não pretende engessar a área, mas consolidá-la, levando em consideração suas práticas e seus processos, derrubando as fronteiras das disciplinas que a formam, no intuito de possibilitar seu crescimento através da pesquisa e de sua prática.
\end{abstract}

Palavras-chave: Design Gráfico Ambiental; Sinalização; Ambientação; Design de Exposições.

\begin{abstract}
This article aims to present and characterize the relatively new area of Environmental Graphic Design, and its subareas: Signage, Placemaking and Exhibition Design, through the review and definition of its concepts. This discussion is not intended to stifle area but consolidate it, taking into consideration their practices and processes, breaking down the boundaries of disciplines that form, in order to promote their growth through research and practice.
\end{abstract}

Key-words: Environmental Graphic Design; Signage; Placemaking; Exhibition Design.

\section{INTRODUÇÃO}

Novas especializações no campo do Design surgem em resposta às enormes mudanças culturais e econômicas da nossa sociedade. Pode-se dizer que o Design Gráfico, que trabalha fornecendo informação para o usuário, seja por meio da linguagem, da imagem ou de símbolos, desdobrou-se em vários caminhos no período compreendido entre o final do século XX e o início do XXI. Uma delas diz respeito à transmissão de mensagens e informações por meio do ambiente construído. Trata-se de várias camadas de comunicação que ajudam a moldar nossa compreensão e senso de lugar (BEDROSSIAN, 2008). É interessante observar que as fronteiras entre disciplinas que interferem no espaço - arquitetura e design - começaram a fundir-se em meados do século $X X$, com influência de outros campos como a psicologia, a 
ergonomia e a comunicação. Neste contexto, a arquitetura trabalha com a concepção do espaço e o design com a disponibilização da informação (HUNT, 2003). Esta fusão veio a ser denominada, posteriormente, de Design Gráfico Ambiental que, com seu conjunto único de habilidades, ajuda-nos a ler o mundo. É um bom exemplo que demonstra o valor e a importância do design em geral, pois desempenha um papel muitas vezes esquecido, mas fundamental na forma como as pessoas interagem com o ambiente.

Embora desde a invenção do papel e das telas de televisão e computador, a maioria das pessoas tenha em mente que o design gráfico atue principalmente nestes meios, cabe lembrar que desde os homens das cavernas e suas inscrições nas paredes até os dias de hoje, uma enorme quantidade de informação é comunicada com sinais e outros objetos localizados no ambiente construído (CALORI, 2007). Na sua configuração atual, a atuação do Design Gráfico Ambiental encontra-se em ambientes tridimensionais como as próprias cidades, os sistemas de transporte de massa, os complexos hospitalares, os centros culturais, educacionais e esportivos, e as lojas de varejo, por exemplo. E compreende desde a sinalização, que quando bem projetada é reconhecida como um dos principais contribuintes para o aumento do bem-estar e segurança; a ambientação, que tem importância pela sua capacidade de criar um senso de lugar para determinado espaço e seu poder de reforçar uma imagem de marca; e o design expositivo, que trabalha com informações interpretativas ao narrar ou contar uma história desde um conceito ou tema até uma empresa e seus produtos. Percebe-se uma área de conhecimento antiga em relação a sua prática, mas nova em termos de teorização e formalização. Trata-se de uma disciplina que vem crescendo e amadurecendo, mas carece ainda de uma maior discussão de seus conceitos e práticas.

Para Campi "[...] uma disciplina se define quando se determina seu objeto de estudo e estabelece seus próprios limites, ainda que polêmicos" (2010, p. 220). Assim, este trabalho tem como objetivo discutir os conceitos relativos ao Design Gráfico Ambiental, dentro da área do Design, e delimitar suas tênues fronteiras. Neste sentido, o conceito de Design Gráfico utilizado corresponde ao de Frascara: "a ação de conceber, programar, projetar e realizar comunicações visuais, produzidas em geral por meios industriais e destinadas a transmitir mensagens específicas a grupos determinados" (2000, p. 19). Já o conceito de Design Gráfico Ambiental, bem como de suas subáreas: sinalização, ambientação e design de exposições, serão levantados ao se pesquisar e caracterizar o campo.

\section{DESIGN GRÁFICO AMBIENTAL}

O Design Gráfico Ambiental apresenta-se como uma área multidisciplinar sem fronteiras nitidamente definidas, formado pela fusão de diferentes disciplinas. Essa falta de definição clara, no entanto, é um dos seus pontos fortes. Segundo Bedrossian (2008), na intersecção entre design gráfico, arquitetura, design de produto e paisagismo vive o Design Gráfico Ambiental. Calori (2007), para quem os projetos na área do Design Gráfico Ambiental são tipicamente complexos, com muitos problemas e subproblemas, que atravessam as fronteiras das várias disciplinas que o compõe, amplia o espectro de disciplinas envolvidas ao acrescentar o planejamento urbano e a arquitetura de interiores, numa escala que vai do macro ao micro (Fig. 1). Destaca-se que as questões ligadas estão principalmente envolvidas à arquitetura e ao design 
gráfico, que durante séculos têm coexistido no ambiente construído. Apesar de cada disciplina falar seu próprio idioma original, tem historicamente tentado um diálogo, preocupadas com os aspectos visuais da informação e da identidade, na formação da idéia de lugar. Segundo Poulin (2012), a arquitetura, através da forma e do espaço, e o design gráfico, através da tipografia, da imagem e do símbolo. Ambas comunicando as sutilezas do tempo e do lugar, ao contar histórias, esclarecendo o propósito de um edifício e ecoando a sua mensagem arquitetônica.

\begin{tabular}{llllll}
$\begin{array}{l}\text { Planejamento } \\
\text { de Cidade / } \\
\text { Design Urbano }\end{array}$ & $\begin{array}{l}\text { Arquitetura } \\
\text { da Paisagem }\end{array}$ & Arquitetura & $\begin{array}{l}\text { Design de } \\
\text { Interiores }\end{array}$ & $\begin{array}{l}\text { Desenho } \\
\text { Industrial }\end{array}$ & $\begin{array}{l}\text { Design } \\
\text { Gráfico }\end{array}$ \\
\hline $\begin{array}{l}\text { Cidades, Vilas, } \\
\text { Campus }\end{array}$ & $\begin{array}{l}\text { Espaços Abertos } \\
\text { Planejados, } \\
\text { Parques }\end{array}$ & Construções & $\begin{array}{l}\text { Espaços } \\
\text { Internos }\end{array}$ & $\begin{array}{l}\text { Objetos de } \\
\text { uso diário e } \\
\text { de trabalho }\end{array}$ & $\begin{array}{l}\text { Objetos que } \\
\text { Comunicam }\end{array}$ \\
\hline Macro & & & & Micro
\end{tabular}

Fig. 1 - Evolução da área de design gráfico ambiental (adaptado de Calori, 2007).

Inscrições clássicas, murais figurativos e superfícies ornamentais tem sido parte da arquitetura e têm influenciado os estilos gráficos e as formas tipográficas e sua representação visual no ambiente construído, demonstrando a integração do design gráfico e arquitetura. Para Poulin (2012), o Design Gráfico tem se integrado com o ambiente construído na formação não só das cidades, mas também na vida de seus habitantes. É o que se verifica, por exemplo, nas marcações de distância nas estradas do Império Romano; nos murais construtivistas ao longo das ruas de Moscou durante a Revolução; nas grandes formas luminosas de Times Square (Nova York), Piccadilly Circus (Londres) e Las Vegas, e na identificação das corporações multinacionais nas suas diversas sedes, todos respondendo diretamente as condições culturais, sociais e econômicas do seu tempo. Ferrara coloca que:

[...] da cidade antiga à pós-moderna, essas marcas escrevem uma história visual
[...]. Porém essa visualidade não acumula, mas cria outros significados. O constante
valor de culto das cidades antigas, grega e medieval é substituído pela visualidade
cenográfica renascentista e barroca com exacerbado valor estético, para expandir-
se na estrutura do valor de troca da cidade comercial oitocentista e culminar na
utópica cidade radiosa do modernismo funcional das primeiras décadas do século
XX. (FERRARA, 2002, p. 124)

Neste contexto, o Design Gráfico Ambiental evoluiu não só por suas melhorias técnicas, mas também pela sua relação integral ao longo do tempo a movimentos culturais ligados a arte e arquitetura. Poulin (2012) classifica em sete fases, muitas vezes sobrepostas, a evolução histórica da integração entre a arquitetura e o design gráfico: (i) O impacto da invenção - 1879-1933, (ii) Arte e Tecnologia: uma nova unidade - 1901-1928, (iii) Estilo e o mercado de massa - 1924-1940, (iv) Entre guerras -1924-1945, (v) Popluxe: a influencia americana - 1946-1963, (vi) Modernismo e Estilo Internacional - 1950-1979, e (vii) Pós-modernismo e depois - 1966-1995. Compreende-se, neste contexto, que prevalecem movimentos históricos e artísticos que diretamente influenciaram e inspiraram as áreas da arquitetura e do design e 
alguns de seus personagens que transformaram o ambiente construído com inovadoras soluções durante o curso do século XX.

Verifica-se, também, que a partir do pós-guerra, com o crescimento econômico verificado ao longo dos anos 1950 e 1960, e principalmente nos países desenvolvidos, as áreas da arquitetura e do design mesclaram-se cada vez mais, em projetos que cresceram em tamanho e complexidade (Fig. 2). É o caso dos centros comerciais e de transporte, por exemplo, que demandaram mais atenção aos sistemas de sinalização e orientação. Avançando algumas décadas, nos anos 1990 e 2000 percebe-se a legitimação do design gráfico ambiental, em que cada novo edifício construído e/ou revitalizado necessita de um sistema de signos (Fig. 3), cada novo terminal rodoviário precisa de mapas e programas de sinalização, os museus devem comunicar enormes quantidades de informação a um público amplo e lojas de varejo precisam marcar presença na mente de seus consumidores.

No Brasil, de acordo com Velho (2007), é na década de 1970 que surgem os primeiros trabalhos relacionados ao Design Gráfico Ambiental, mais especificamente no que tange à sinalização. Assim como em outros países surge de demandas que mesclam, como já pontuado, as áreas da arquitetura e do design. Para um campo relativamente novo, percorreu-se um longo caminho em poucos anos.
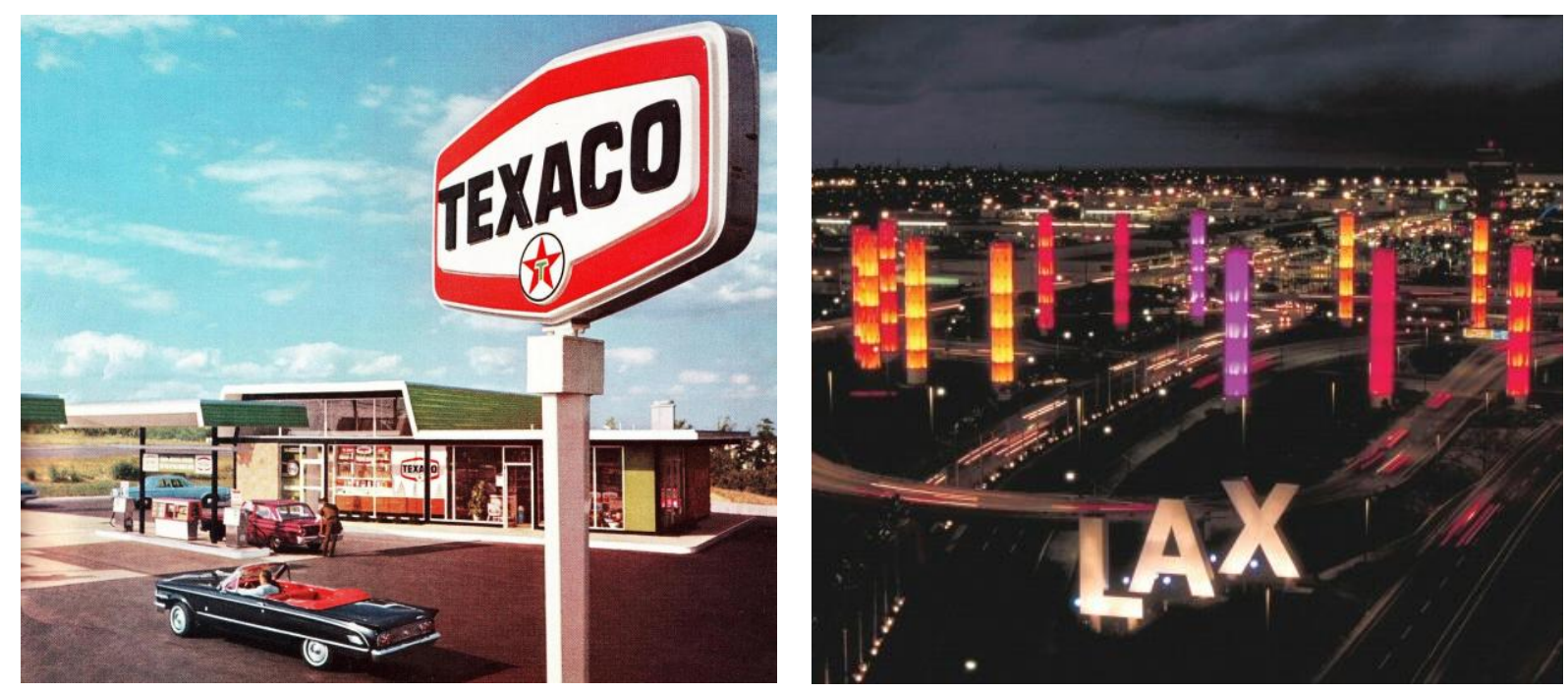

Fig. 2 - Sinalização/Ambientação Texaco (anos 1930) por Walter Dorwin Teague | Fig. 3 - Sinalização/ Ambientação LAX Aeroporto Los Angeles, (2000) por Selbert Perkins Design (Acervo do Autor).

O Design Gráfico Ambiental pode ser entendido como a interface visual entre a informação (design gráfico) e a edificação (arquitetura). É interessante observar que, em princípio, informação e edificação podem ser consideradas de difícil combinação. Mas, segundo Ferrara, "[...] o designer tem uma função não só abrangente, mas, sobretudo, integradora de um modo de pensar o espaço para qualificá-lo, para dar a coerência que o identifica" (2002, p. 55). Constata-se que o profissional da área deve exibir competência no uso de ferramentas para trabalhar com tipografia, cores e formas, possuir conhecimento em processos de fabricação, assim como, na leitura do espaço e em orientação espacial (wayfinding). O designer gráfico ambiental tem 0 
cuidado de moldar a informação ao seu contexto, associando-a as questões ambientais e sociais.

Neste cenário, a SEGD (Society for Environmental Graphic Design), trabalha com o termo Design Gráfico Ambiental. Já a ADG (Associação dos Designers Gráficos) trabalha esta vertente apenas como design ambiental, dividindo-a em duas categorias: de sinalização e de ambientação, também denominado design total. Unindo as terminologias, a adotada neste trabalho - Design Gráfico Ambiental - aproxima-se da utilizada em inglês Environmental Graphic Design. Ainda que a palavra ambiental esteja vinculada muitas vezes a questões ecológicas, defende-se o uso dessa nomenclatura por ser a que mais se aproxima do sentido prático desejado. Salienta-se que ambiente é aqui entendido como o entorno de um indivíduo, conforme Gibson define: "[...] a essência de um ambiente é o entorno de um indivíduo" (1986, p. 43). Este não é conformado por limites tátcteis, como paredes ou muros, mas estabelecido pelo observador durante o processo de leitura e interpretação dos códigos presentes na linguagem. Por essa perspectiva, segundo Jacob (2007), a noção de informação não se separa da noção de ambiente e é concebida em unicidade. Nesse sentido, o uso da palavra gráfico é justificado por representar o registro físico da informação que carece, na maioria das vezes, de meios mecânicos para ser produzido, ao mesmo tempo em que delimita a forma com a qual será disponibilizada. O não uso da palavra gráfico ou o uso da palavra visual no lugar de gráfico, por exemplo, deixam o escopo ainda bastante amplo, não colaborando para a delimitação da área.

Unindo as classificações da ADG e da SEGD, bem como o estudo evolutivo da área feito por Hunt (2003) (fig. 4), neste trabalho, serão consideradas três as práticas do Design Gráfico Ambiental: sinalização (architectural signing), ambientação (placemaking) e design de exposições (interpretative design). Todas abarcam o desenvolvimento de um sistema informativo visualmente coeso específico para um determinado local.
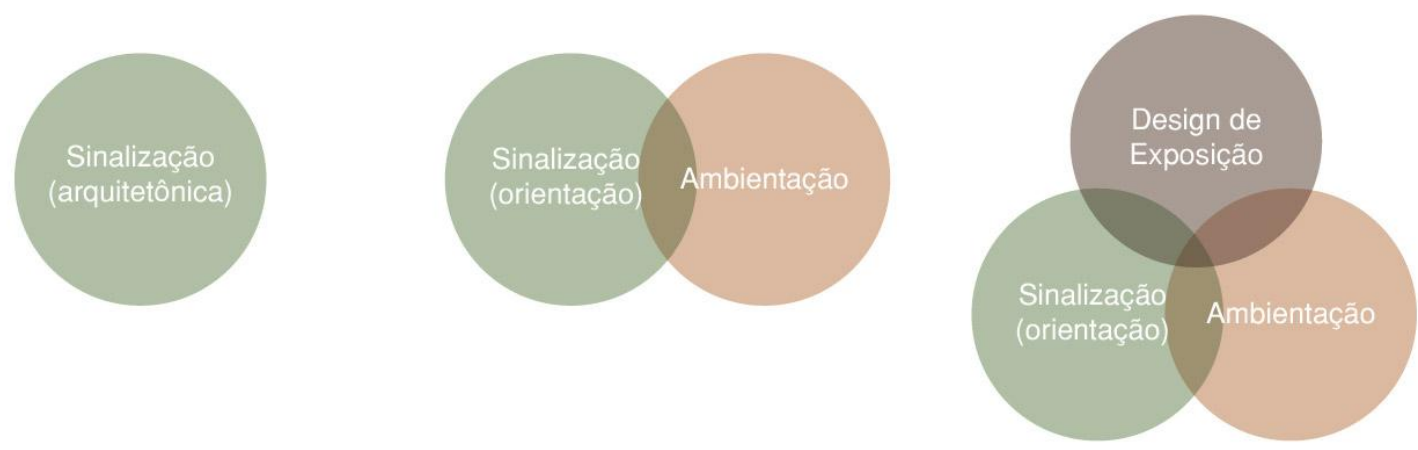

Fig. 4 - Evolução da área de design gráfico ambiental (adaptado de Hunt, 2003).

Pode-se dizer que a sinalização procura otimizar, por vezes até viabilizar, a utilização e o funcionamento de espaços, sejam eles abertos ou construídos através de elementos direcionais, locacionais e informativos, em diversos formatos e materiais. A ambientação se apresenta como importante local de comunicação e interação dos 
consumidores com os produtos e a identidade visual da marca (desde o estande até o ponto de venda - PDV). O design de exposições, por sua vez, trabalha com narrativas, utilizando elementos com o intuito de proporcionar uma experiência que é proposital e original, criando uma relação forte e memorável entre o visitante e o conteúdo da exposição.

\subsection{Sinalização}

Encontrar o caminho não é um dom ou uma capacidade inata que qualquer um tem ou não tem. É uma condição para a própria vida. [...] Viver com nossas respectivas formas de navegar (wayfinding) é uma premissa básica para a nossa liberdade e a nossa autoconfiança. Saber onde estou, a minha localização, é condição prévia para saber onde eu tenho que ir, onde quer que seja. (AICHER apud UEBELE, 2007, p. 7)

Segundo a SEGD, dentro dos sistemas gráficos para ambientes, o processo de sinalização pode ser definido como o planejamento, projeto e especificação de elementos gráficos no ambiente construído ou natural. Estes elementos são usados para comunicar informações específicas em sistemas de identificação, informação, direção, interpretação, orientação, regulamentação e ambientação. Já segundo a ADG (2000), o design de sinalização procura possibilitar a utilização e o funcionamento de espaços, sejam eles abertos ou construídos. Este tipo de projeto costuma ser inserido em espaços abertos, (praças e parques e estacionamentos), em edificações com certo nível de complexidade (shopping centers, supermercados, escolas e universidades, aeroportos, rodoviárias, hospitais e clínicas, museus e espaços culturais, bancos, lojas, restaurantes) além de eventos de grande abrangência (olimpíadas, feiras mundiais, etc.).

Embora o termo sinalização possa ser considerado muito amplo e genérico, segundo Velho (2007), ao se modificar ao longo dos anos, reflete a complexidade, ao incorporar novos atributos no seu desempenho (tais como o seu relacionamento com o ambiente, a introdução de uma linguagem gráfica mais expressiva e uma maior liberdade na escolha e no uso de tipografias, cores, com a introdução da informática). Neste contexto, entram dois outros dois conceitos importantes: señalética e wayfinding.

O termo senãlética, estabelecido por Costa (1989 e 2007), pode ser considerado como uma evolução da prática da sinalização, aplicada aos problemas particulares de informação espacial, que se integra ao espaço, ao ambiente e contribui para reforçar uma identidade. A adaptação da señalética ao meio é uma premissa fundamental desta disciplina e um dos principais fatores que a distinguem da sinalização. $O$ projeto deve conferir um valor agregado ao ambiente em que se encontra; deve melhorar a experiência do visitante e facilitar a fluidez entre espaços. Ela também responde à necessidade da informação ou orientação, provocada e ampliada pelo fenômeno contemporâneo da mobilidade: deslocamento de grupos de indivíduos de diferentes procedências geográficas, condições sócio-econômicas e culturais distintas, gerando novas situações. Constata-se que a señalética procura não impor a atenção do público, não provocar impacto, nem recorrer à atração estética, pois sua linguagem é predominantemente sintetizada, não discursiva e evita a retomada visual. Seu princípio é o da economia generalizada: máxima informação com 
o mínimo de elementos e com o mínimo de esforço do receptor para sua identificação e compreensão. Sua presença é silenciosa, sua ocupação é discreta, e deve desaparecer de imediato do campo de conhecimento do usuário. Pode-se, então, definir a señaletica como o conceito mais funcional de sinalização.

Arthur e Passini (1992), discutindo o termo wayfinding, articulam-no a um processo dinâmico para solucionar os problemas de mobilidade das pessoas no ambiente. Para Ross (2012), wayfinding pode ser descrito como os processos cognitivos que todas as pessoas executam ao se deslocar pelo espaço. Na sua forma mais simples, está ligado a três componentes: (i) identificar onde se está como um ponto de origem para o caminho/percurso; (ii) leitura contínua da paisagem enquanto se desloca através dela, uma experiência multissensorial, formando feedback para tomada de decisão; e (iii) identificar o destino quando se chegou. Ou seja, percebe-se que enquanto planejamento espacial e comunicação, wayfinding é mais do que projetar um sistema de sinalização, é um critério essencial e uma parte integrante de qualquer processo de design. Com a abordagem do wayfinding questionam-se os paradigmas do design de sinalização, notadamente os de caráter funcionalista, assim como se reforça a necessidade de atendimento a questões específicas como, por exemplo, de informações direcionadas a deficientes visuais e físicos, denotando preocupação com questões de acessibilidade.

Neste contexto, nota-se que os conceitos de señalética e wayfinding reforçam e distinguem a prática profissional e teórica da sinalização como o planejamento, projeto e especificação de elementos gráficos no ambiente construído ou natural. Com as funções básicas de identificar, orientar e informar, a sinalização proporciona ao usuário entender e deslocar-se pelo espaço, fornecendo autonomia. Mas pode também ambientar e particularizar a informação, propiciando identidade ao espaço. A sinalização deve ser ao mesmo tempo, funcional (legível e inequívoca) e contextualizada ao ambiente.

\subsection{Ambientação}

O ambiente construído que vivenciamos em nossas vidas diárias continuamente depende do design gráfico ambiental para comunicar informações e identidade, moldar a nossa percepção global e memória de um senso de lugar e, finalmente, animar, enriquecer e humanizar nossas vidas. (POULIN, 2012, p. 11)

Originado de placemaking, conceito criado nos anos 1970 significando o modo pelo qual os seres humanos transformam os espaços, dando significado aos lugares, ambientando-os, a ambientação, para Calori (2007), cria uma imagem distinta para um local. O que separa ambientação, no sentido do Design Gráfico Ambiental, de outras formas de ambientação, é a comunicação de informação explícita. Sem essa intenção de comunicação explícita, a ambientação se torna um exercício de arquitetura ou de design de interiores. O que não impede que os designers não possam se integrar aos profissionais dessas disciplinas, a fim de potencializar as ambientações.

Assim, as ambientações estão intimamente ligadas à promoção e ao consumo de produtos e serviços e, dessa forma, opõem-se ao design de exposições, outra vertente do Design Gráfico Ambiental. Aqui o objetivo principal é atrair, entusiasmar e encantar o consumidor criando uma experiência no ponto de venda (lojas e quiosques, por exemplo), ambientes temáticos (parques de diversões) e eventos (shows, convenções e lançamentos de produtos). Ao criar esta experiência compartilhada, 
percebe-se que o projeto que tenha entendimento do que é significativo para o seu público tende a ter o reconhecimento deste, que passa a se envolver e se apropriar do espaço. Nesse sentido, a ambientação pode ser influenciada por condições sociais, econômicas, culturais, políticas e históricas, no desenvolvimento dos seus processos de concepção.

Deve-se ter em mente que o propósito da ambientação consiste em possibilitar a promoção e a venda de produtos e serviços. Trata-se de uma área que se relaciona com o mundo das marcas, tornando-a ainda mais complexa. Um mundo em que o sucesso não depende apenas da marca ou do produto, mas também de estratégias de organização do espaço, desde a entrada até a finalização do processo de compra, compreendendo toda a experiência. Todavia, estas estratégias, muitas vezes debaixo de pretensa neutralidade, podem contribuir efetivamente para a construção da imagem de uma marca e o aumento do consumo de um determinado produto ou uso de um determinado serviço. A questão aqui é relação emocional e a experiência, através da disponibilização de informações no espaço, que conecta a marca com o consumidor.

\subsection{Design de Exposições}

As exposições converteram-se em fenômenos socioculturais insubstituíveis entre as atividades habituais [...]. Constituem em nossos dias, tanto para o museu como para outras entidades (fundações, casas de cultura, galerias comerciais, feiras, etc.), um instrumento indispensável de apresentação, interpretação e difusão das coleções, objetos [...] e conceitos socioculturais. Paralelamente ao aumento do interesse e da demanda pública, as exposições têm-se desenvolvido conceitual e tecnicamente, requerendo cada vez maiores esforços materiais e humanos para a realização de projetos cada vez mais complexos. Neste contexto o design é um elemento essencial para o êxito de uma exposição. (FERNÁNDEZ e FERNÁNDEZ, 2010, p. 22)

Para Calori (2007), o Design de Exposições (interpretative design) conta uma história sobre o significado de um conceito ou tema (por exemplo, a democracia ou ciência), um objeto, um espaço, um evento, uma figura histórica, uma empresa e seus produtos, e assim por diante. Nesse contexto, observa-se que informação interpretativa é mais frequentemente expressa sob a forma de exposições, onde a questão preponderante é a narrativa, com a qual se quer comunicar e/ou contar um relato. Para Hughes (2010), toda exposição se inicia com uma narrativa, que pode ser desde muito simples até uma história complexa baseada em pesquisas minuciosas. A estratégia da exposição determina em detalhes como será desenvolvida esta narrativa dentro de um espaço determinado. As exposições podem ser compostas de um local em si, artefatos físicos, imagens, meios audiovisuais e conta, muitas vezes, com recursos interativos. Como tal, exige que se considere uma ampla gama de fatores, incluindo o conteúdo da mostra, a divisão ou classificação dos objetos e os modos de envolver os visitantes.

Já a taxionomia ou a classificação das exposições pode admitir tantas variações tais como critérios museológicos e técnicos, e podem aplicar-se para destacar as características e usos deste meio de comunicação. Locker (2011) traz como exemplos de exposições desde feiras comerciais e experiências de marca (que neste trabalho são classificadas como ambientação), até atrações temáticas, exposições mundiais, 
galerias de museus, centros turísticos, casas históricas e instalações de arte. Para Fernández e Fernández (2010), devem-se distinguir também as formas de apresentação de acordo com a evolução das relações entre espaço expositivo e conteúdo: exposições podem ser permanentes ou temporárias, com uma vida útil de cinco anos ou cinco dias; e podem variar em escala desde pequenas telas até o tamanho de uma pequena cidade, no caso de exposições mundiais. Os autores ainda destacam que em um sentido histórico e de acordo com o desenvolvimento sociocultural, as funções de uma exposição podem ser classificadas, de forma não excludente, em: simbólicas (relativo ao valor de ostentação dos objetos), documentais (ligado ao valor informativo ou científico dos objetos), e estéticas (inerente ao valor artístico dos objetos).

Neste cenário, o design de exposição procura materializar a ideia, tornando-a experiência nos espaços relacionados com a cultura material coletiva das sociedades. Sendo importante observar que a narrativa, ou seja, a atividade de contar histórias, com frequência inclui a história, a preservação, a conservação e a educação.

\section{DISCUSSÃO DOS RESULTADOS}

O Design Gráfico Ambiental configura-se como uma área que se consolidou e se legitimou através de sua prática profissional. Trazendo aspectos ligados ao design gráfico e a arquitetura, e a consequente interação com o ambiente, ele dividiu-se em três subáreas: sinalização, ambientação e design de exposição (fig. 5). Todas possuem suas especificidades e seus pontos em comum. Além disso, a integração de diferentes disciplinas, tais como planejamento urbano, paisagismo, arquitetura, arquitetura de interiores, desenho industrial e design gráfico, possibilita uma riqueza de abordagens. Observa-se que colaboração é a palavra chave e o pensamento fora de suas fronteiras é essencial.

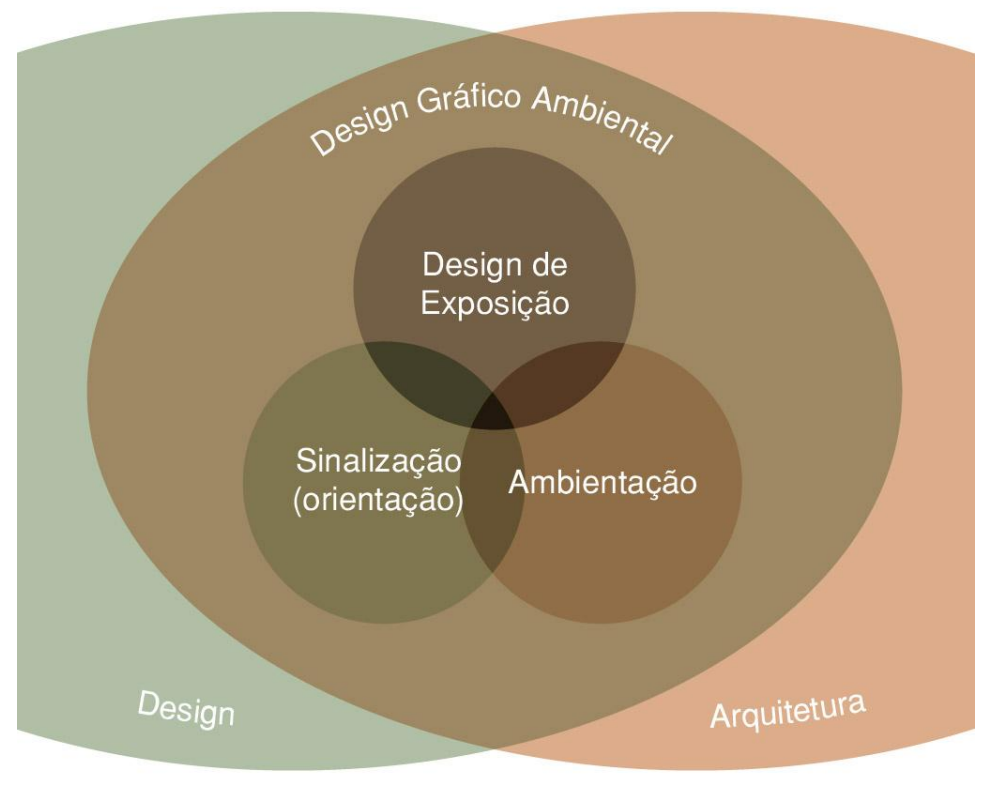

Fig. 5 - Design gráfico ambiental e suas áreas. 
Pode-se articular, então que a área de sinalização e orientação trabalha com estratégias de design que direcionam, informam e identificam espaços. A área da ambientação cria e da forma a lugares e ambientes. E a área do design de exposições, por sua vez, educa e interpreta as informações. Destaca-se que estas subáreas do Design Gráfico Ambiental muitas vezes trabalham de forma integrada. Por exemplo, ao mesmo tempo em que a sinalização e orientação estão informando, podem servir para unificar visualmente um espaço, desempenhando o papel de ambientação (grande parte dos centros comerciais). Da mesma forma, uma ambientação também pode servir para expor informações sobre um produto/serviço (maioria das lojas e parques temáticos). E o contrário também, uma exposição pode ambientar um espaço (maioria dos museus).

No que se refere aos conceitos propriamente ditos, embora as definições fechadas possam prejudicar o desenvolvimento de uma disciplina, engessando-a, ao mesmo tempo, desempenham um papel vital nas formas em que esta se manifesta, se consolida e se renova. Além disso, as definições dão ferramentas para a crítica reflexiva e aprofundamento deste campo de conhecimento. Após a caracterização da área e de suas subáreas, têm-se então como conceitos:

Design Gráfico Ambiental $\rightarrow$ área multidisciplinar que une arquitetura e design no planejamento dos espaços e de seus elementos gráficos (informações) em um sistema visualmente coeso, com o intuito de sinalizar, ambientar e expor.

Sinalização $\rightarrow$ planejamento, projeto e especificação de elementos gráficos no ambiente construído ou natural, com o intuito identificar, informar, direcionar e orientar.

Ambientação $\rightarrow$ planejamento, projeto e especificação de elementos gráficos no ambiente construído ou natural, com o intuito de particularizar e persuadir.

Design de Exposição $\rightarrow$ planejamento, projeto e especificação de elementos gráficos no ambiente construído ou natural, com o intuito de interpretar, informar e educar.

Percebe-se que o campo do Design Gráfico Ambiental tem um enorme impacto sobre a cultura visual e a identidade social. Desta forma, a compreensão da complexa integração cultural da informação com o ambiente construído ou natural é um componente imprescindível do projeto.

\section{CONSIDERAÇÕES FINAIS}

O campo do Design Gráfico Ambiental só recentemente foi reconhecido como uma disciplina dentro das profissões de design. Assim sendo, pouca documentação de relevância ou avaliação crítica pode ser encontrada tratando da história e do contexto atual. $\mathrm{O}$ ambiente construído que vivenciamos em nossas vidas diárias continuamente depende de design gráfico para comunicar informações de uma identidade, moldar a percepção global e a memória, além do senso de lugar e, finalmente, animar, enriquecer e humanizar a vida. 
Com este texto espera-se trazer à tona a discussão sobre o Design Gráfico Ambiental e lançar uma luz aos conceitos, às práticas e aos processos desta área que, como salientado, vem crescendo e amadurecendo. É o momento de compartilhar ideias e começar uma discussão para o crescimento do campo e em benefício do ambiente construído e de seus usuários.

O futuro do Design Gráfico Ambiental parece estar na totalidade de uma dada experiência do usuário, que começa bem antes dele entrar em um ambiente físico e vai além das possibilidades que se abriram com telefones celulares e as informações e os mapas personalizados (a eletrônica e miniaturização abriram uma nova etapa onde a relação usuário e ambiente vai alterar-se dinamicamente, trazendo mudanças culturais e econômicas). Embora ainda exista a necessidade básica de encontrar e determinar as informações que devem ser disponibilizadas, com tanto estimulo visual e tecnologia disponível, é ainda mais importante ser capaz de encontrar facilmente o caminho certo, sentir-se bem e aprender com o ambiente. As fronteiras entre design e arquitetura estão cada vez mais tênues, e a capacidade de oferecer uma combinação entre informação e ambiente cria diferentes oportunidades para conectar as pessoas com os lugares.

\section{REFERÊNCIAS}

ADG Associação dos Designers Gráficos (Brasil). ABC da ADG: glossário de termos e verbetes utilizados em design gráfico. São Paulo: ADG, 2000.

BEDROSSIAN, Rebecca. Environmental Graphic Design. Communication Arts. March/April 2008. pag. 84/102.

CALORI, Chris. Signage and Wayfinding Design: A Complete Guide to Creating Environmental Graphic Design Systems. : Wiley, 2007.

CAMPI, Isabel. La idea y la materia. Vol 1. El diseño de produto em sus orígenes. Barcelona: Gustavo Gili, 2007.Coleção GG Diseño.

COSTA, Joan. Señalética. Barcelona: CEAC, 1989.

COSTA, Joan. Señalética Corporativa. Barcelona: Costa Punto Com, 2007.

CURY, Marília Xavier. Exposição: concepção, montagem e avaliação. São Paulo: Annablume, 2006.

FERNÁNDEZ, Luis Alonso; FERNÁNDEZ, Isabel García. Diseño de Exposiciones. Concepto, instalación y montaje. 2॰ edição. Madri: Alianza Forma, 2010.

FERRARA, Lucrécia. Design em espaços. São Paulo: Rosari, 2002.

FRASCARA, Jorge. Diseño Gráfico y Comunicación. 7॰ edição. Buenos Aires: Infinito, 2000.

GIBSON, James. The ecological approach to visual perception. Boston: Houghton Miffin, 1986.

HUGHES, Philip. Diseño de exposiciones. Barcelona: Promopress, 2010.

HUNT, Wayne. Environmental Graphics: Projects \& Process. New York: Harper Collins, 2003. 
JACOB, Eduardo Louis. Gráfico Ambiental: típicos e tópicos. 2007. Dissertação (mestrado). São Paulo - Pontifícia Universidade Católica de São Paulo, Programa de Estudos Pós-Graduados em Comunicação e Semiótica.

LOCKER, Pam. Exhibition Design. Lausanne: AVA, 2011. Basic Interior Design 02.

POULIN, Richard. Graphic Design in the Built Environment: A 20th Century History. Minneapolis: Rockport, 2012.

ROSS, Mark. The Wayfinders. Disponível em: <http://dotdash.com.au/> Acessado em 14 mar. 2012.

SEGD - Society for Environmental Graphic Design. Disponível em: <http://www.segd.org> Acessado em 14 mar. 2012.

UEBELE, Andreas. Signage System \& Information Graphics. London: Thames \& Hudson, 2007.

VELHO, Ana Lucia de Oliveira Leite. O Design de Sinalização no Brasil: a introdução de novos conceitos de 1970 a 2000. 2007. Dissertação (mestrado) - Pontifícia Universidade Católica do Rio de Janeiro, Curso de Pós-graduação em Design do Departamento de Artes \& Design. 